\title{
IMPLEMENTASI METODA MATRIX BERBASIS DISKRIT UNTUK MENDETEKSI OBYEK BERGERAK DI DALAM AIR
}

1)

2)

\author{
Purwanto ${ }^{1)}$, Unang Achlison ${ }^{2)}$ \\ Teknik Elektronika, Sekolah Tinggi Elektronika \\ dan Komputer email: purwanto@stekom.ac.id \\ Teknik Elektronika, Sekolah Tinggi \\ Elektronika dan Komputer email: unang@ \\ stekom.ac.id
}

\section{Abstract}

Number of fish seed can be measured by means of conventional observation using eye senses. But when the fish seed measured pretty much it will take a long time (not efficient) and cause incorrect measurement results (inaccurate). The accuracy of calculation of fingerlings is crucial trust between seller and buyer.

During this time a sensor is used to detect the amount of fish seed is passed through a transparent hose using a light sensor (Light Dependent Resistor) and photodiode sensors as infra red light receiver. The level of accuracy of the sensor lies in the intensity of the light beam is received so that the sensor will be impaired if airya murky and there are air bubbles pass through the sensor so that the fish count error occurs.

This research will be conducted design counters the number of fingerlings using infra red phototransistor sensor with a frequency of $20 \mathrm{KHz}$ to fish and then processed using the logic matrix. Results matrix logic into the data input to be processed by a microcontroller as the basis of results of calculation of the amount of fish.

Development model studies using models of $R \& D$ (research and development) that produce a product in the form of the final product. Experiments were carried out using the type and length of catfish fingerlings with a length of $3 \mathrm{~cm}$ to $5 \mathrm{~cm}$. Fish seed count tool has been tested to catfish farmers in the village Siwarak Ungaran City.

The trial results calculators fish seeds have difference of $3 \%$ of the calculated results Manual or accuracy of calculation results have fish reaches $97 \%$, then a counter of fish seed is acceptable to be used by catfish farmers.

Keywords: calculating the number of fingerlings, matrix logic NAND, Microcontroller

\section{PENDAHULUAN}

Produksi dan perdagangan ikan di Indonesia merupakan salah satu kegiatan ekonomi yang penting seperti pada gambar 1 . Kegiatan produksi harus diimbangi oleh pengembangan teknologi tepat guna yang dibutuhkan untuk meningkatkan dan mendukung pemasaran ikan.

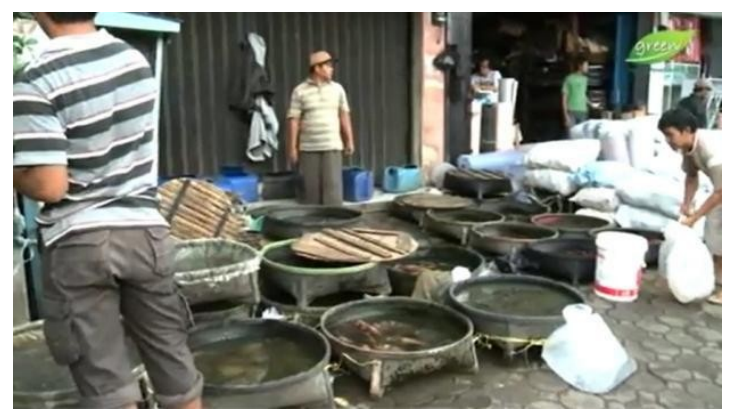

Gambar 1. Perdagangan Ikan
Langkah yang menentukan dalam pemasaran ikan adalah proses hitung benih ikan. Para petani ikan biasanya menghitung jumlah benih ikan hasil pemuliaan terlebih dulu sebelum di jual ke pasaran. Cara menghitung benih umumnya dengan memakai takaran, yaitu dengan memakai sendok dan dihitung perekor untuk benih ukuran gelondongan seperti ditunjukkan gambar 2 .

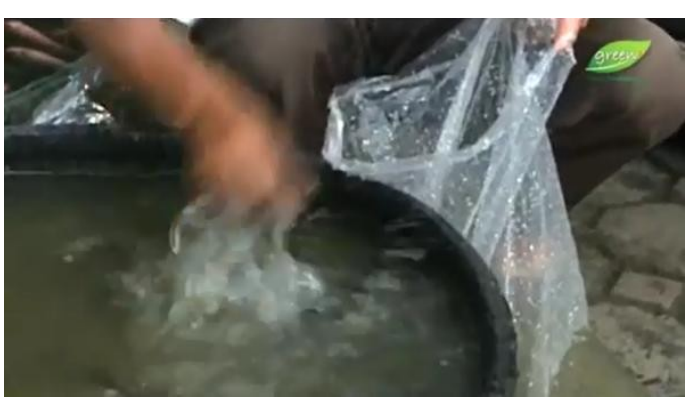

Gambar 2. Menghitung secara manual 
Petani ikan masih melakukan penghitungan jumlah benih ikan dengan cara konvensional. Tetapi bila benih ikan yang dihitung cukup banyak maka akan memerlukan waktu yang lama.

Kondisi ini dapat disimpulkan bahwa petani ikan melakukan proses penghitungan jumlah benih ikan masih secara konvensional sehingga tidak efisien. Hal ini disebabkan karena pengamatan mengguakan indra mata pada benih ikan sangat dipengaruhi oleh tingkat ketelitian seseorang dan besar kemungkinan hasil hitung ikan terjadi kesalahan. Ketepatan perhitungan sangat menentukan kepercayaan antara penjual dan pembeli.

Selama ini alat sensor yang digunakan untuk mendeteksi jumlah benih ikan yang dialirkan melalui pipa transparan yang melewati sensor photodioda penerima cahaya infra red kemudian menjadi pulsa digital sebagai data input dalam proses perhitungan ikan (Widagdo Purbowaskito, 2014). Hasil pengujian alat penghitung benih ikan

menunjukkan akurasi terbaik pada penggunaan pipa transparan dengan diameter $1,8 \mathrm{~cm}$ atau $3 / 4$ inci yaitu $91.2 \%$.

Berdasarkan pada uraian tersebut di atas, penulis menyimpulkan bahwa alat penghitung benih ikan hanya cocok untuk ikan ukuran besar (pipa transparan berdiameter $1,8 \mathrm{~cm}$ ) dan metode penelitian yang digunakan adalah uji laboratorium. Penulis merumuskan pokok-pokok masalah sebagai berikut:

a. Bagaimana membuat alat penghitung benih ikan yang cocok untuk benih ikan yang mempunyai ukuran kecil (pipa transparan berdiameter $1 \mathrm{~cm})$ ?

b. Bagaimana metoda yang digunakan agar air keruh dan gelembung udara yang

melewati pipa transparan tidak menyebabkan kesalahan hasil hitung benih ikan?

Untuk mengatasi masalah tersebut perlu dilakukan upaya agar penghitungan benih ikan dilakukan oleh alat berbasis Microcontroller yang dapat menghitung jumlah benih ikan yang dimasukkan kedalam alat tersebut secara efisien, akurat dan cepat bila dibandingkan dengan perhitungan secara manual. Dalam perkembangan teknologi perlu dilakukan riset atau penelitian yang bersifat eksperimental sehingga didapatkan alat yang berdayaguna. Penelitian ini

bertujuan sebagai berikut :

a. Membuat alat penghitung benih ikan yang tidak tergantung intensitas berkas cahaya yang diterima dan bersifat hasil uji eksperimental.

b. Merumuskan metoda yang digunakan sehingga air keruh dan gelembung udara yang melewati pipa penyaluran diameter $1 \mathrm{~cm}$ tidak menyebabkan kesalahan hasil hitung benih ikan.

c. Menggunakan Microcontroller untuk mengolah input data dari sensor benih ikan sehingga menjadi hasil perhitungan jumlah ikan secara otomatis.

\section{KAJIAN LITERATUR}

a. Phototransistor

Phototransistor adalah merupakan sebuah transistor yang akan saturasi pada saat menerima sinar infra merah dan cut off pada saat tidak ada sinar infra merah. IR Module adalah sebuah rangkaian yang terdiri dari sebuah phototransistor dan filter yang terbentuk dalam satu modul di mana collector dari phototransistor adalah merupakan output dari modul ini. Pada saat phototransistor cut off maka tidak terjadi aliran arus dari collector menuju ke emitter sehingga collector yang merupakan output dari IR Module akan berkondisi high. Apabila phototransistor saturasi maka arus mengalir dari collector ke emitter dan output dari IR Module akan berkondisi low.
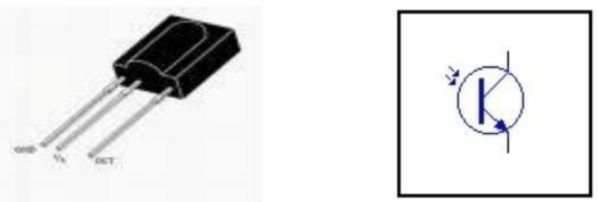

Gambar 3. Sensor Phototransistor (Sumber : www.vishay.com)

Simbol suatu phototransistor pada gambar 5 terlihat bahwa basis dalam keadaan terbuka. Ini merupakan cara yang biasa untuk mengoperasikan suatu phototransistor. Tingkat sensitivitas cahayanya dapat dikendalikan melalui tahanan basis yang variabel (basereturn transistor), tetapi basis biasanya dibiarkan terbuka untuk mendapatkan sensitivitas yang maksimum untuk diberi 
cahaya. Rangkaian ini berfungsi sebagai sensor penerima cahaya infra merah yang dipancarka oleh rangkaian LED sumber cahaya infra merah. Rangkaian ini mempunyai komponen utama adalah foto transistor sebagai penerima cahaya dari LED infra merah. Foto transistor ini sudah dilengkapi dengan rangkaian band pass filter yang hanya melewatkan frekuensi antara $20 \mathrm{kHz}$ sampai $60 \mathrm{kHz}$ (Vishay Semiconductors, 2012).

\section{b. Logika Matrix NAND}

Elektronika digital adalah sistem elektronik yang menggunakan signal digital. Signal digital didasarkan pada signal yang bertegangan 5 Volt dan 0 Volt. Signal digital dilambangkan dengan notasi aljabar atau logika 1 dan 0 . Notasi dengan logika 1 melambangkan terjadinya hubungan dan notasi 0

melambangkan tidak terjadinya hubungan. Contoh yang paling mudah untuk memahami pengertian ini menggunakan saklar lampu. Ketika saklar lampu ON berarti terjadi hubungan atau berlogika high dan dinotasikan 1. Ketika saklar lampu OFF berarti tidak terjadi hubungan atau berlogika low dan dinotasikan 0 .

Elektronik digital atau atau rangkaian digital apapun tersusun dari apa yang disebut sebagai gerbang logika. Gerbang logika melakukan operasi logika pada satu atau lebih input dan menghasilkan ouput yang tunggal. Output yang dihasilkan merupakan hasil dari serangkaian operasi logika berdasarkan prinsip prinsip aljabar boolean. Dalam pengertian elektronik, input dan output ini diwujudkan dan voltase atau arus (tergantung dari tipe elektronik yang digunakan). Setiap gerbang logika membutuhkan daya yang digunakan sebagai sumber dan tempat buangan dari arus untuk memperoleh voltase yang sesuai.

Dasar pembentukan gerbang logika adalah tabel kebenaran (truth table) dan salah satunya adalah NAND. Gerbang NAND mempunyai dua atau lebih dari dua sinyal input (A dan B) dan mempunyai satu sinyal output (Y). Dalam gerbang NAND, apabila salah satu input berlogika low maka output akan berlogika high.

Gerbang logika NAND pada Datasheet nama lainnya yaitu IC TTL 7400 mempunyai tabel kebenaran yang ditampilkan pada gambar 6 .

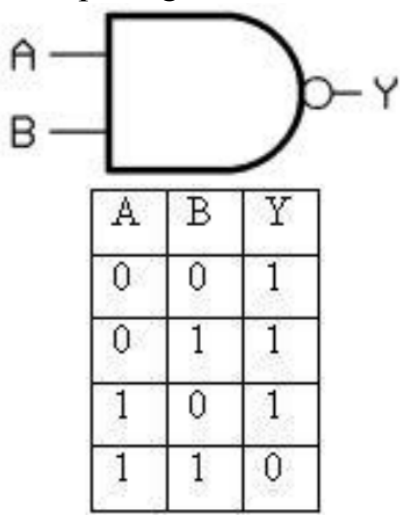

Gambar 4. Simbol NAND Logic Gate dan Truth Table

(Sumber: https://fayezfeztiawan.wordpress.com/2013/03/26/gerbang-logikadasar-logic-gate/)

c. Microcontroller AT89S51

Menurut Djoko Tri Hastono (2009), Microcontroller AT89C51 mempunyai 40 pin yang sesuai dengan Microcontroller 8031 dan memiliki susunan pin seperti Gambar 5.

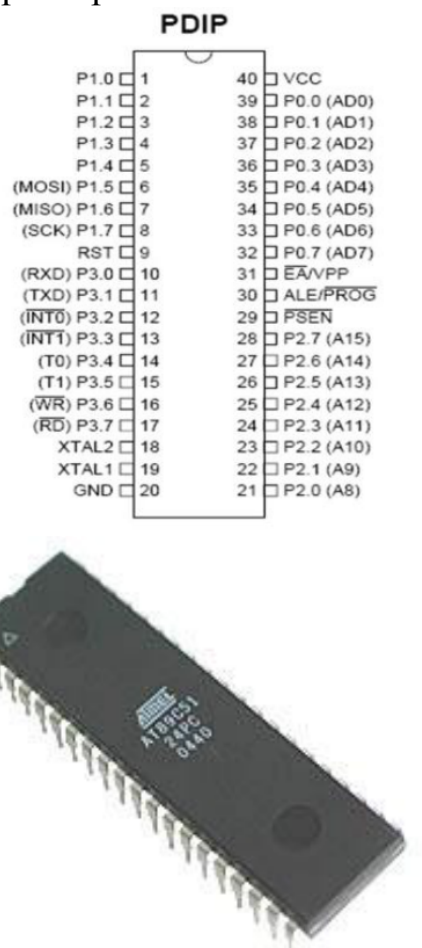

Gambar 5. Microcontroller AT89S51

(Sumber : www.forumsains.com) 


\section{METODE PENELITIAN}

Metode penelitian dalam rancang bangun Alat Penghitung Jumlah Benih Ikan menggunakan research and development $(\mathrm{R} \&$ D), menurut Borg dan Gall (1989) dalam Sugiyono (2011) menjadi 6 langkah sebagaimana ditampilkan gambar 6 .

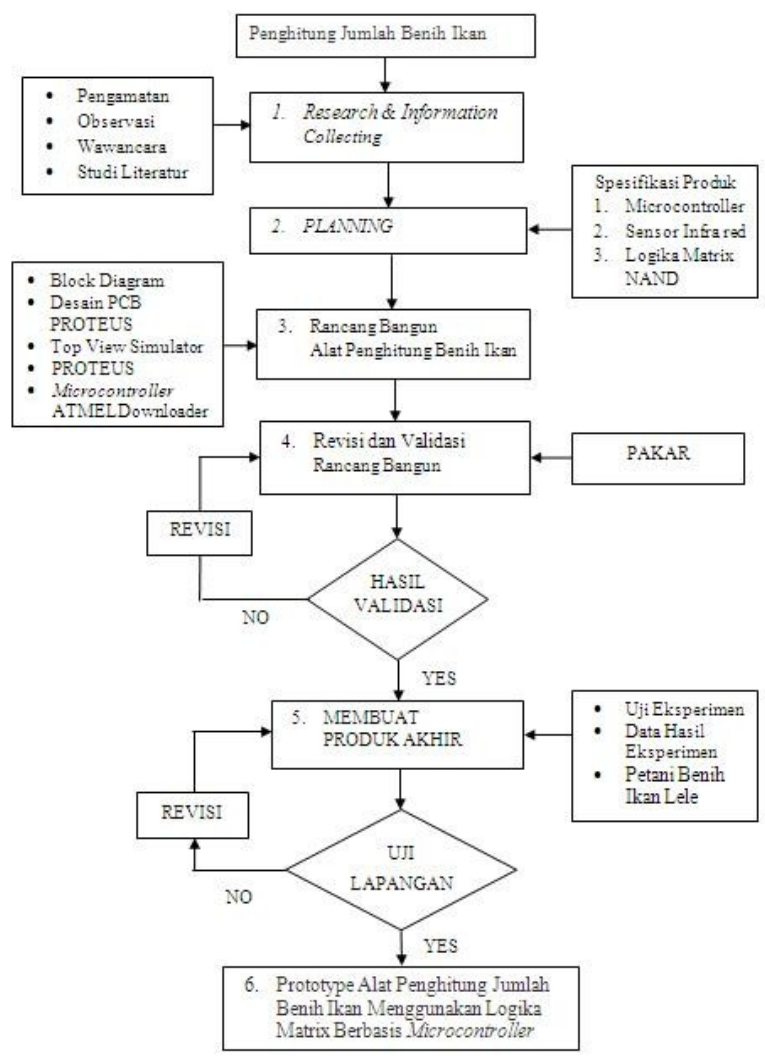

Gambar 6. Metode Penelitian

\section{HASIL DAN PEMBAHASAN}

a. Diagram Block

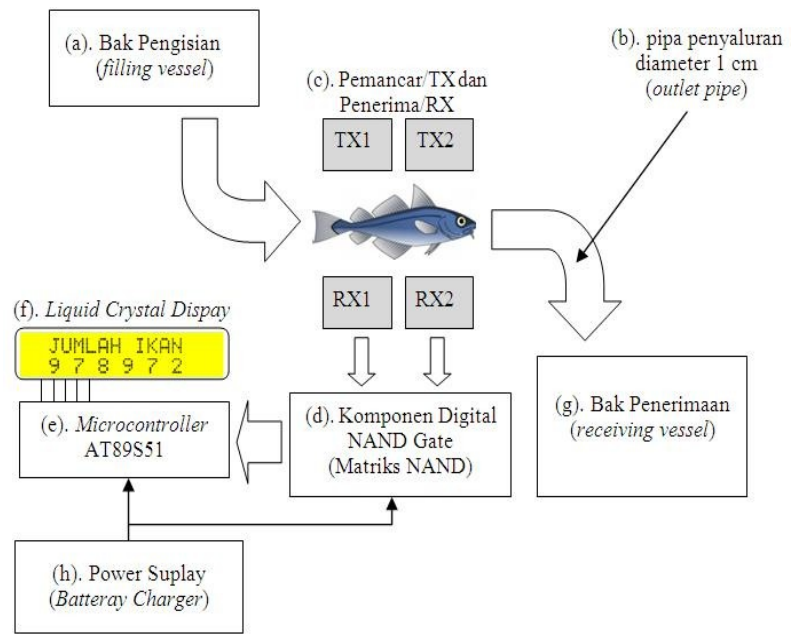

Gambar 7. Block Diagram Alat Hitung Benih Ikan
Penjelasan Diagram Alat Hitung Benih Ikan yaitu:

a) Bak pengisian (filling vessel) sebagai Input air dan ikan.

b) Pipa transparan diameter $1 \mathrm{~cm}$ untuk media saluran ikan.

c) Sensor pemancar (TX) dan penerima (RX) Infra Merah.

d) Microcontroller akan menghitung jumlah benih ikan

e) Liquid Crystal Display menampilkan data hasil hitung.

f) Bak penerimaan (receiving vessel) sebagai Output ikan.

g) Power Sumber transformator $5 \mathrm{~V}$ dan ACCU 6V.

Alat hitung ikan menggunakan LED Infra Red dan sensor phototransistor bila cahaya tidak terhalang akan ON dan apabila cahaya terhalang maka akan OFF. Terdapat 4 (empat) kondisi yang akan terjadi:

Tabel 1. Matrix Kondisi dan Logika yang terjadi pada sensor ikan

\begin{tabular}{|c|c|c|c|c|}
\hline \multirow{2}{*}{ No } & \multicolumn{2}{|c|}{ Sensor 1 } & \multicolumn{2}{c|}{ Sensor 2 } \\
\cline { 2 - 5 } & Kondisi & Logika & Kondisi & Logika \\
\hline 1. & tidak terhalang & 0 & tidak terhalang & 0 \\
\hline 2. & tidak terhalang & 0 & terhalang & 1 \\
\hline 3. & terhalang & 1 & tidak terhalang & 0 \\
\hline 4. & terhalang & 1 & terhalang & 1 \\
\hline
\end{tabular}

Prinsip kerja Alat Penghitung Benih Ikan yaitu ikan yang akan dihitung terlebih dahulu dimasukkan ke dalam bak pengisian (filling vessel) untuk dialirkan melalui pipa penyaluran (outlet pipe). Bak pengisian (filling vessel) dan pipa penyaluran (outlet pipe) ditunjukkan seperti pada gambar 8 .

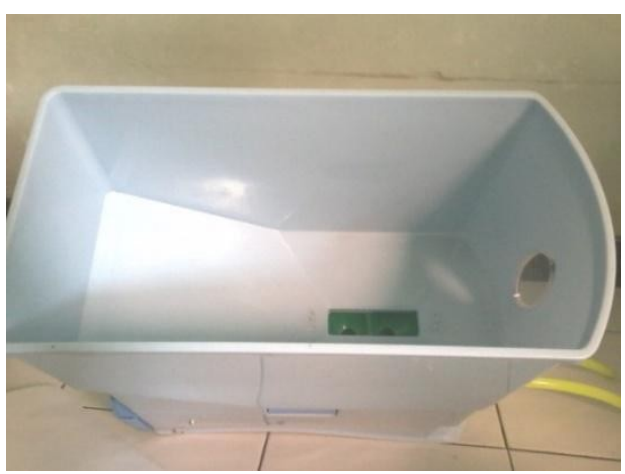

(a) 


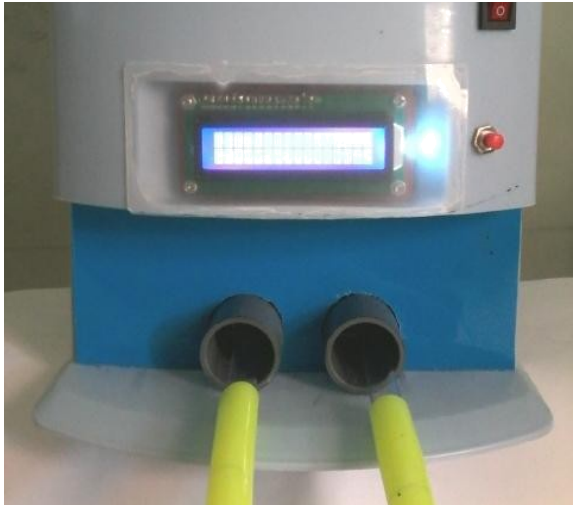

(b)

Gambar 8. (a) Bak pengisian atau filling vessel, dan (b) Pipa penya-luran atau outlet pipe

Alat hitung benih ikan akan mulai dihitung bila kedua input gerbang logika NAND melalui sensor Infra Red terhalang badan ikan maka ikan mulai dihitung. Hasil logika matrix ini akan menjadi input data untuk diolah oleh Microcontroller kemudian menggunakan Liquid Crystal Display untuk menampilkan data hasil hitung ikan. Modul Alat Penghitung Benih Ikan ditunjukkan seperti pada gambar 10 .

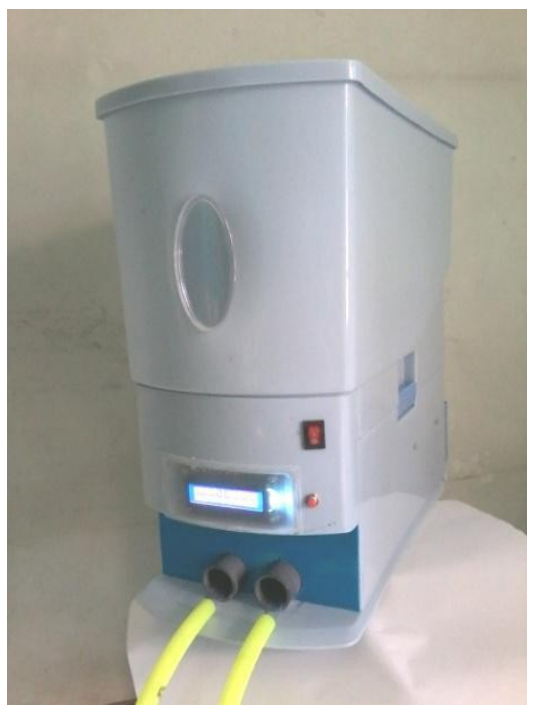

Gambar 9. Alat Penghitung Benih Ikan
Hasil uji coba alat hitung benih ikan kepada petani ikan lele di desa Siwarak Kota Ungaran ditunjukkan tabel 2.

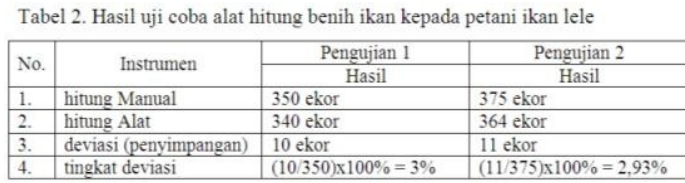

Berdasarkan Tabel 2, maka hasil uji coba alat hitung benih ikan mempunyai deviasi (penyimpangan) rata-rata $2,9 \%$ terhadap jumlah semestinya atau mempunyai Akurasi hasil penghitungan ikan mencapai 97\%.

\section{SIMPULAN}

A. Simpulan sebagai berikut

a. Alat Penghitung Jumlah Benih Ikan Menggunakan Logika Matrix initelahberhasildibuat

menggunakan sensor phototransistor penerima cahaya infra red dengan frekuensi $20 \mathrm{KHz}$ sebagai media untuk mendeteksi ikan yang dilewatkan pada pipa transparan berdiameter $1 \mathrm{~cm}$.

b. Akurasi hasil penghitungan menggunakan alat hitung benih ikan mencapai 97\% terhadap jumlah ikan semestinya.

B. Kelemahan

Kapasitas penghitung benih ikan dibawah seribu maka tingkat akurasi alat penghitung benih ikan ini mempunyai deviasi (penyimpangan) rata-rata $2,9 \%$ terhadap penghitungan manual oleh petani benih ikan.

C. Kelebihan

Kapasitas penghitung benih ikan hingga puluhan ribu.

- Pengoperasian yang sama pada alat penghitung benih ikan ini akan menghasilkan tingkat akurasi dan mempunyai deviasi (penyimpangan) rata-rata yang sama.

- Tingkat akurasi penghitungan manual oleh petani benih ikan akan memiliki akurasi lebih rendah dan mempunyai deviasi (penyimpangan) rata-rata akan jauh lebih besar dikarenakan keterbatasan indra mata dari petani benih ikan. 


\section{REFERENSI}

Amir D. 2014. Analisis Kecepatan Reaksi Sensor Terhadap Gelombang Cahaya Infra Merah Dan Laser. Jurnal Litek (ISSN: 1693-8097) Volume 11 Nomor 1, Maret 2014: hal. 8-12

Borg, W.R. \& Gall, M.D. Gall. 1989. Educational Research: An Introduction, (5th ed.). New York: Longman

Djoko Tri Hastono. 2009. Sistem Pengendali dan Pengukur Suhu Pada Mesin Penetas Telur berbasis Mikrokontroler At89S51. Graduates thesis, Universitas Negeri Semarang

Effendi, I. 2004. Pengantar Akuakultur . Penebar Swadaya. Jakarta

Minarni, Saktioto, Gita Lestari. 2013. Prosiding Semirata FMIPA Universitas Lampung. Semirata 2013 FMIPA Unila, halaman 167

Petruzella, FD. 1996. Elektronika Industri. Jakarta : Andi

Sugiyono.2009.MetodologiPenelitian ManajemenPendidikan. Bandung: CV. Alfabeta

Suseno. 2000. Pengelolaan Usaha Pembenihan Ikan Mas. Penebar Swadaya. Jakarta

Vishay Semiconductors. 2012. Document Number: 81665 Rev. 1.4, 28 Mar 2012

WidagdoPurbowaskito.2014.Rancang Bangun Alat Penghitung Benih Ikan Menggunakan Sensor Optik Fototransistor Berbasis Mikrokontroler ATMEL ATMEGA8. Universitas Gajah Mada, Yogjakarta, Jawa tengah 